\title{
BMJ Open Are there also negative effects of social support? A qualitative study of patients with inflammatory bowel disease
}

\author{
Alexander Palant, Wolfgang Himmel
}

To cite: Palant A, Himmel W. Are there also negative effects of social support? A qualitative study of patients with inflammatory bowel disease. BMJ Open 2019;9:e022642. doi:10.1136/ bmjopen-2018-022642

- Prepublication history for this paper is available online. To view these files, please visit the journal online (http://dx.doi. org/10.1136/bmjopen-2018022642).

Preliminary results were presented at the International Conference on Health and Person-Centered Care in the Digital Society, April 2017, Halden, Norway.

Received 6 March 2018 Revised 3 October 2018 Accepted 19 0ctober 2018
D) Check for updates

(c) Author(s) (or their employer(s)) 2019. Re-use permitted under CC BY-NC. No commercial re-use. See rights and permissions. Published by BMJ.

Department of General Practice, University Medical Center, Göttingen, Germany

Correspondence to Professor Wolfgang Himmel; whimmel@gwdg.de

\section{ABSTRACT}

Objective Social support is considered an important resource in coping with chronic conditions. By conducting a series of interviews with people who suffer from inflammatory bowel disease (IBD), we received the impression that social support in face-to-face or online communication could also be a source of stress and strain. The aim of our study was to better understand and describe possible negative effects of social support. Design This is a secondary analysis of narrative interviews. The interviewees were selected using a maximum-variation sampling approach. Grounded theory and the 'OSOP' (one sheet of paper) method were applied to categorise those parts of the interviews that touched on the negative effects of social support.

Setting The open-end interview collection took place throughout Germany from September 2011 to June 2012. Most of the participants were interviewed in their homes, some in the Department of General Practice in Göttingen. Participants 42 patients with IBD.

Results Two interrelated categories emerged: (1) unwanted confrontation and (2) undesirable reactions. The interviewees perceived social support as negative, especially if they felt overwhelmed and/or if they had not asked for it. Consequently, some of our interview partners developed strategies to prevent coming into social contact with others or stopped talking entirely about their disease. Conclusion While social support is usually conceptualised and perceived as a positive resource in chronic disease, it sometimes turns into a negative experience and may end in social isolation and deteriorate health. This process also happens in online support groups and increases anxiety when exchanging with other people on the internet. Before motivating ill people to seek contact with others, they should know about the negative effects of social support.

\section{INTRODUCTION}

Inflammatory bowel diseases (IBDs) are chronic relapsing conditions, such as Crohn's disease (CD) and ulcerative colitis (UC), that affect the gastrointestinal tract and are currently incurable. ${ }^{1}$ Diarrhoea with or without passage of blood, stomach pain and weight loss are the most common symptoms described by the patients. There are approximately 200 cases per 100000 inhabitants in the Western world and 300000 people

\section{Strengths and limitations of this study}

The study uses the participants' perspective to identify the effects of social support.

- The open character of this interview study allowed participants to report the negative effects, if any, of social support without feeling forced to address this issue.

- The results of the study can inform friends and family and the medical professionals that unwanted information or other undesirable forms of support could complicate the attempts of chronically ill patients to adjust to their illness.

- Since we did not balance the pros and cons of social support, this study should not be read as a plea against social support.

affected in Germany alone, most of them between the ages of 15 and $35 .^{2}$

IBD profoundly affects the patients' life situations, quality of life (QoL), health and well-being. ${ }^{3}$ According to a meta-synthesis of qualitative studies, ${ }^{4}$ many people with IBD endure stress, pain and fatigue; they report high levels of anxiety and depression and a poorer QoL. They experience a constant 'push and pull' conflict: they push to be normal, but the disease pulls them back. One of the most effective ways to cope with challenges from chronic conditions-and thus also with IBD-is with social support. ${ }^{5-7}$

According to Prang et $a l^{6}{ }^{6}$ social support can be defined as information that helps individuals believe they are cared for, loved, esteemed, valued and belong to a network of communication and mutual obligation. Research has shown that social support is associated with good physical health, reduces and prevents illness, moderates life stress, ${ }_{5}$ positively influences anxiety and depression, ${ }^{5}$ and improves QoL $^{8}$ and well-being. ${ }^{9}$ The protective role of social support on mental health is also documented. Patients who are supported feel more warmth and affection and can better cope with the disease than patients who have less social support. ${ }^{10}$ Vice 
versa, withdrawing from friends and reducing social support results in isolation and feeling low in mood, as a previous qualitative interview study with patients with IBD in South East London found. ${ }^{11}$

Social support has various sources:

1. Family and friends provide effective support based on close relations, ${ }^{10}$ where the size of a social network, particularly the number of friends, is associated with improved outcomes and recovery. ${ }^{12}$

2. Coworkers have a positive impact on work stress ${ }^{13}$ and can even act as a buffer in work-family conflicts. ${ }^{14}$

3. Face-to-face support groups can be seen as a system to complement medical treatment through mutual care, sharing information and a helpful exchange of experiences, ${ }^{15}$ resulting in increased knowledge about conditions, enhanced coping and disease management, motivation, and support for behavioural change and maintenance. $^{1617}$

4. The anonymous environment of online support groups is especially important for those who feel stigmatised and have difficulties talking about their condition; more than half of the messages posted in online support groups provided or solicited emotional support. ${ }^{18}$ Despite these positive findings, there is also some alarming research about the negative effects of social support. Patients reported feeling a loss of control because of the need for assistance in daily struggles, difficulties fulfilling the expectations of their friends and family, or uncertainty of people in their social network about how to address their disease, which can increase their own uncertainties. ${ }^{19}$ Some chronically ill patients even complained about increasing conflicts with friends or partners because of unwanted social support. ${ }^{20}$

There are several studies specifically focused on patients with IBD where they talk-in addition to other things-about negative experiences with their social network. ${ }^{37}$ However, none of these studies had systematically investigated the possible negative effects of social support. By conducting a series of interviews with people who suffer from IBD, we received the impression that contacts with family, friends, colleagues or peers in faceto-face or online communication could also be a source of stress and strain. Following Katz et $a l^{21}$ call also to look at negative variables in their inflluence on IBD-QoL and resiliency, we aimed to determine, on the basis of a large sample of in-depth interviews, whether patients with IBD experienced negative effects from social support and if so, how these experiences can be categorised and which role the different sources of social support had played.

\section{METHODS}

\section{Context and setting}

For this study, we examined interviews, which are simultaneously the basis for the German website project www. krankheitserfahrungen.de, a part of the DIPEx International network (http://www.dipexinternational.org). The websites contain video, audio and text interview sequences of people talking about their lives with a chronic condition. The main goal is to show the range of patient experiences and, by doing so, to provide free, authentic and reliable scientific information for other people with similar diseases. ${ }^{22}$ The German project currently presents ten different health-related issues: diabetes, chronic pain, epilepsy, IBD, three cancer modules (prostate, breast and colon), medical rehabilitation, attention deficit hyperactivity disorders in children and adolescents and eating disorders.

\section{Overall study design}

This is a qualitative study. Narrative interviews were conducted for the health issue 'IBD' on krankheitserfahr ungen.de using a maximum-variation sampling approach and analysed using Grounded Theory.

\section{Recruitment}

We tried to include a broad variety of people with regard to gender, age, social and ethnic background, disease severity and so on that would cover the diversity of illness experiences. We used various recruitment strategies, including newspaper ads and social media, and asked self-support groups, family doctors and gastroenterologists to inform possible participants about our project. We also used different wording in the ads targeting specific groups of patients (eg, immigrants, people with less severe symptoms etc).

\section{Data collection}

The interview collection took place throughout Germany from September 2011 to June 2012. AP and WH (sociologists and experienced in interviewing) conducted narrative face-to-face interviews with patients at their homes, during a stay at rehabilitation clinic or at the Department of General Practice in Göttingen, according to the patient's preference.

We asked the participants at the beginning of each interview simply to tell us about their experiences with the disease from the first time they noticed some health problems. The participants were told that our research did not have any particular focus, only that we were interested in their personal experiences with the illness. This way, the participants had the opportunity to tell us what was important to them regarding their condition in their own words and according to their individual preferences (for more details, see Palant $e t a l^{23}$ ).

After these stories were finished, open-ended questions were asked to generate further illness narratives. The additional interview guide was developed beforehand and was used to ask some additional questions about related issues such as practical strategies to cope with the illness, current problems, financial burdens because of the IBD, information needs and suggestions for other patients. The interviews lasted approximately $90 \mathrm{~min}$ on average.

Field notes or memos (interviewer's first reactions, impressions of the patient's living situation and first thoughts about the main topics for the participants) 
were made during and after the interview and were used to enrich data analysis afterwards. Interviews were audiotaped and transcribed verbatim. Each participant received a copy of the transcribed interview and was asked to give us consent to use the interview on the project's website and for scientific research such as this study.

\section{Data analysis}

The analysis started with 'initial coding' of the material, as usual for Grounded Theory. ${ }^{24}$ Simultaneously, the authors wrote down their thoughts and possible connections within and between important topics in the interviews ('memoing').

For the presentation of the interview material on the website, we then used the 'OSOP' (one sheet of paper) technique, ${ }^{22}$ which requires the raters to note all important issues from the 'initial coding' to one specific topic on a single sheet of paper. This technique helps to identify patterns and common themes within the data, to explore how the main topics are connected, and allows a deeper understanding of patient experiences. ${ }^{22}$

After the launch of the new health issue 'IBD' on the website in 2014, we started an in-depth analysis of the interviews in 2015 and first explored the issue of food and diet. ${ }^{23}$ During this analysis, we became aware of the ambivalent role of social support for patients with IBD and decided to explore this issue in more detail in the following years, with a special focus on 'negative effects'. During the coding, we followed Prang and colleagues' definition of social support. ${ }^{6}$ Since 'negative effects of social support' was an 'a priori' theme, we coded the components of the interviews relating to this 'a priori' theme and grouped them into meaningful clusters, that is, subthemes. The preliminary interpretations were regularly discussed during project meetings. Those discussions helped us to recognise, formulate and refine our main category and subthemes, which are the basis for the results of this study. ATLAS.ti was used as data indexing software to help with the analysis.

To enhance the validity of our data analysis, we could build on the support of an Advisory Board as part of an 'audit trail'. ${ }^{25}$ This board consisted of experts within the respective module, including those suffering from the health condition. The advisory board provided input on the literature review, ideas on key areas for sampling categories, topics for the interview guideline and helped find interview partners. Moreover, given the overwhelming adoption of the positive role of social support, our approach can be characterised as a search for 'disconfirming evidence' as Creswill and Miller ${ }^{25}$ put it and may thus protect us against proclivity to find conforming evidence.

\section{Patient and public involvement}

Patients and public were not involved in the development and writing of this study.

\section{Results}

A total of 42 interviewees took part in the study. Their average age was 42 (median; minimum: 18; maximum: $76) ; 54 \%$ of the interviewees were women. Twenty-five of the participants had CD, 15 suffered from UC and two from indeterminate colitis $(\mathrm{UC} / \mathrm{CD})$. Duration of illness ranged from 5 to over 40 years (table 1 ).

Social support was a recurrent topic in every interview. Our participants spoke mostly about positive experiences with their friends and family, other patients or colleagues and customers, especially if they showed respect and understanding and helped them, preferably in a relaxed atmosphere. One of our interview partners told us, for instance, that it helps him to be regularly asked about his well-being and also that he is shown forbearance that not everything is completed as fast as previously.

I was laid off work after my illness for 5 weeks. And seeing that I also have customers, I was deeply impressed by their sympathy and that they enquired how I was, and also that they said: if it takes longer now and then, or if anything is the matter, then that just is so... That I am acknowledged as a human being and not just as someone who is paid and who then has to function accordingly. (ID 22, male, 54 years)

Nevertheless, from time to time, the interview partners also told us about unpleasant situations or conversations with members of their social network or people on the internet. We examined these passages in the interviews closely and found patterns that are best represented in two interrelated categories: (1) unwanted confrontation and (2) undesirable reactions, both with several subcategories.

\section{Unwanted confrontation \\ Confrontation with unwanted information by social contacts}

Some patients sometimes wished not to think about their disease, at least from time to time. During such times, they felt annoyed if family members, friends or other persons asked them about their condition. ID 31 did not like being confronted with additional information by her partner while trying not to think about her illness. This made her feel overwhelmed.

My husband also deeply cares about all this. Although I have to say that it sometimes gets to be too much and I tell him 'I don't want to listen to all this crap, leave me in peace'. (ID 31, female, 48 years)

Support groups were a good way to meet other people with similar conditions, receive tips about coping with the disease and get emotional support. Nevertheless, talking extensively about the symptoms and therapies drew attention to the negative aspects of the disease and led to discomfort and anxiety, especially if the participants were just in remission.

Self-support group(s), as I noticed, (are) dominating life for so many people that it depressed me terribly. 
Table 1 Sampling characteristics

\begin{tabular}{|c|c|c|c|c|c|c|c|}
\hline ID & Diagnosis & Age & Gender & Marital status & Employment & $\begin{array}{l}\text { Year of } \\
\text { diagnosis }\end{array}$ & $\begin{array}{l}\text { Current state at time of the } \\
\text { interview }\end{array}$ \\
\hline 1 & $\mathrm{CD}$ & 30 & $\mathrm{~F}$ & Married & Full time & 2000 & No gastrointestinal complaints \\
\hline 2 & CD & 53 & M & Divorced & Full time & 1971 & Some complaints \\
\hline 3 & $C D$ & 31 & $\mathrm{~F}$ & Single & Part time & 2009 & Acute flare \\
\hline 4 & UC & 48 & $\mathrm{~F}$ & Married & Unemployed & 2005 & Acute flare \\
\hline 5 & $\mathrm{CD}$ & 31 & $\mathrm{~F}$ & Married & Retired & 2000 & No complaints \\
\hline 6 & UC & 40 & $\mathrm{~F}$ & Married & Full time & 2004 & Acute flare \\
\hline 7 & UC & 30 & M & Single & Full time & 2005 & No complaints \\
\hline 8 & UC/CD & 31 & $\mathrm{~F}$ & Single & Full time & 2007 & Acute flare \\
\hline 9 & $C D$ & 52 & $\mathrm{~F}$ & Married & Unemployed & 2004 & Acute flare \\
\hline 10 & $C D$ & 76 & $\mathrm{~F}$ & Married & Retired & 1988 & No complaints \\
\hline 11 & $C D$ & 36 & M & Single & Unemployed & 1997 & Acute flare \\
\hline 12 & UC & 35 & M & Single & Full time & 2006 & No complaints \\
\hline 13 & UC & 72 & M & Married & Retired & 1960 & No complaints \\
\hline 14 & $\mathrm{CD}$ & 35 & $\mathrm{~F}$ & Married & Unemployed & 2005 & Acute flare \\
\hline 15 & UC & 30 & $\mathrm{~F}$ & Single & Full time & 1999 & No complaints \\
\hline 16 & CD/UC & 31 & M & Single & Unemployed & 1997 & Acute flare \\
\hline 17 & UC & 24 & M & Single & Student & 2003 & No complaints \\
\hline 18 & UC & 43 & $M$ & Single & Full time & 1998 & No complaints \\
\hline 19 & $\mathrm{CD}$ & 18 & M & Single & Student & 2010 & No complaints \\
\hline 20 & $C D$ & 24 & $\mathrm{~F}$ & Single & Student & 2010 & Acute flare \\
\hline 21 & UC & 34 & $\mathrm{~F}$ & Married & Full time & 2010 & No complaints \\
\hline 22 & UC & 54 & M & Married & Self-employed & 2010 & Some complaints \\
\hline 23 & $C D$ & 60 & M & Married & Full time & 1992 & No complaints \\
\hline 24 & CD & 51 & $\mathrm{~F}$ & Married & Unemployed & 1977 & No complaints \\
\hline 25 & UC & 42 & $M$ & Single & Self-employed & 2009 & No complaints \\
\hline 26 & UC & 55 & M & Single & Retired & 1984 & No complaints \\
\hline 27 & $C D$ & 72 & M & Single & Retired & 2009 & Some complaints \\
\hline 28 & $C D$ & 45 & $\mathrm{~F}$ & Single & Full time & 1981 & Some complaints \\
\hline 29 & UC & 17 & $\mathrm{~F}$ & Single & Student & 2009 & No complaints \\
\hline 30 & CD & 56 & $\mathrm{~F}$ & Married & Retired & 1978 & Some complaints \\
\hline 31 & $C D$ & 48 & $\mathrm{~F}$ & Married & Unemployed & 1995 & Acute flare \\
\hline 32 & CD & 58 & M & Married & Unemployed & 1998 & Acute flare \\
\hline 33 & UC & 57 & M & Single & Unemployed & 2007 & Acute flare \\
\hline 34 & UC & 40 & $\mathrm{~F}$ & Single & Full time & 1998 & Some complaints \\
\hline 35 & $C D$ & 32 & $\mathrm{~F}$ & Single & Full time & 2008 & Some complaints \\
\hline 36 & CD & 28 & M & Single & Full time & 2000 & Some complaints \\
\hline 37 & $C D$ & 60 & M & Married & Self-employed & 2008 & Some complaints \\
\hline 38 & CD & 40 & $\mathrm{~F}$ & Single & Self-employed & 1985 & Some complaints \\
\hline 39 & $C D$ & 53 & $\mathrm{~F}$ & Single & Full time & 1976 & Some complaints \\
\hline 40 & $C D$ & 43 & M & Married & Full time & 2001 & No complaints \\
\hline 41 & $C D$ & 30 & $\mathrm{~F}$ & Single & Full time & 1999 & No complaints \\
\hline 42 & $C D$ & 30 & $\mathrm{~F}$ & Single & Full time & 1999 & Some complaints \\
\hline
\end{tabular}

CD, Crohn's disease; UC, ulcerative colitis. 
At first sight, there are certainly times when this is all true for me as well, simply because it's so pertinent. But I refuse to be determined by this. I want to focus on my job, my family, my own life. I don't feel like letting this become so obsessive a subject. (ID 15, female, 30 years)

Then I meet people who have the same illness, and then we exchange news and views, and at times also more details about the illness. It's then the main subject, and there's also these reconvalescence times or self-support groups, what new medication is there, and what do you do in this situation and that, and they talk for more than an hour and a half about when they take which pills. That's exhausting for me. (ID 39, female, 53 years)

\section{Confrontation with a possible negative future}

The course of the illness was mostly uncertain. Most people with IBD hoped to get better with time. Therefore, it was difficult for them to hear from others about possible health problems in the future. Instead of helpful answers, ID 21 was confronted with a possible change for the worse during a support group meeting. Information from other participants got her worried about her own course of the disease.

Then I asked all possible questions to do with the illness. And that was helpful, but also terrifying on occasion. (...) Not nice to see this soon what it might be like later. (ID 21, female, 34years)

Even if you could find endless information about a disease online, it was very hard for someone who is not a medical expert to know what information could be trusted. Reading about health-related information on the internet could therefore lead to more anxiety and uncertainty.

Reading about the symptoms on the internet has upset me slightly. (...) 'cause I thought, 'nope, these are individual cases, it doesn't have to be like this for you'. The real worries started actually when I experienced these boosts (in the illness) myself. (ID 12, male, 35 years)

\section{Confrontation with people who are feeling much better than} oneself

People in support groups sometimes tend to compare each other's experiences about who was more successful in coping with her or his condition. This group dynamic could lead to a type of competition instead of emotional support. Because of this experience, ID 28 questioned her own condition and why she was not getting better, which led to anxiety and made her quit the group.

For myself, at some point I'll not participate in the group anymore 'cause I don't want to listen to (more repeated stories of) what someone attained for themselves, like with veterans: I have even more wounds. I have had even more operations, and I have still better prescriptions.' (ID 28, female, 45 years)

\section{Undesirable reactions \\ Pity}

Some interview partners did not want to be pitied, especially during times when they did not suffer. Some developed strategies to prevent coming into social contact with others or stopped talking about their disease entirely. ID 41 did not feel that she was strongly affected by her illness and, consequently, did not want people to think that either and therefore feel pity for her. She wanted to be treated normally.

It's not as hard for me anymore. It's harder when people pity you. Me, I don't need pity. (ID 41, female, 30 years)

The same person explained later that she had the urge to 'prove' to other people that she did not feel restricted or 'different' because of her condition. Somehow, she needed be the same as before.

I met a pal from university recently, and he didn't know anything about this bag-thing (artificial anus). I didn't want to shock him either, and I didn't want him to pity me. But then we went out (in the evening) and I told him, 'There, I'm still as you knew me before. I still step onto the dance floor and do my bit and all'. This all didn't change me in that respect. (ID 41 , female, 30 years)

The same person talked about her experiences at the workplace. She also wanted to be treated normally because she did not consider herself to be changed.

Even the colleagues and my boss. And that's not because I'm ashamed to have this, quite the contrary, I'm proud that I'm still me despite this bag. That I go out and have fun. You know, I'm not going to have that taken away from me. But I did notice that many pity me, rather. And that sure is not something I want. (ID 41 , female, 30 years)

\section{Overreacting}

People from the social network of our interview partners sometimes expressed more concerns about the health of our participants than they did themselves. This could lead to uncertainty and anxiety, especially if persons with IBD felt able to cope with their condition. Furthermore, social support could be an additional burden. ID 12 described how his family's and friends' concerns had a negative effect on his health. Because persons in his social network thought his condition was bad, he became more anxious. In this case, friends and family changed his self-awareness and influenced his perceived health.

People who visited me started crying because they thought, 'what's the matter with him?' and then this 
caught hold of me, too, so I started to be really afraid and panicky. (ID 12, male, 35 years)

ID 36 did not suffer because of his disease. His relatives were making a 'big deal' out of his illness, maybe even more than it should be. Nevertheless, he understood them and thought this reaction was normal, but it bothered him anyway.

Relatives, when they learnt about this, it was of course almost the end of the world. When I was 16 and saw their reaction, one didn't make such a fuss, to be quite honest. I took my medication and felt quite okay at that moment. Relatives are always the most upset, of course. (ID 36, male, 28 years)

The reaction of her social circle to the illness made ID 8 unhappy. She was disappointed because no one reacted the way she wanted. Emotional support was either extreme or missing. She experienced negative emotions, so she came to the conclusion it was better not to talk about her condition.

Very few people know what to make of this. When it's explained to them, they either don't take it seriously at all or they are profoundly shocked. Either way is somewhat over the top, in my view. Very few people know how to take that in a really cool way. (ID 8 , female, 31 years)

\section{'Positive' stigma}

Some interviewees complained about unwanted attention from friends after the diagnosis was made. ID 15 had the impression her friends showed interest in the disease but not in the person who suffered from it. She did not want special treatment because she did not want to be defined by her illness.

Well, I realised that some people who before at some party or other didn't really think I was interesting at all then thought, fascinating, long-time illness. Not what I want at all. (ID 15, female, 30 years)

\section{DISCUSSION}

The interviews with IBD patients for the website project krankheitserfahrungen.de revealed many positive episodes in regard to social support. Therefore, it was not the purpose of this study to reject the social support hypothesis, nor did we intend to balance the positive effects of social support against the negative ones. The aim of the study was to take a closer look at possible negative effects of social support and to describe them in more detail. They can be summarised in two main categories: (1) 'unwanted confrontation' and (2) 'undesirable reactions'. Both categories describe different aspects of dissatisfying or sometimes even harmful encounters and relations of our participants with persons in their close social environment, at work or with other peers online.
The interviewees perceived social support as negative, especially if they felt overwhelmed and/or if they had not asked for it. Similar experiences were reported in regard to social support at work or in online communities.

\section{Unwanted confrontation}

The main focus of unwanted confrontation was on negative experiences of our participants in face-to-face encounters and online support groups; for example, with undesirable information about the illness or talking to other persons with IBD who were feeling much better or worse than the interviewees did. Both situations were considered unpleasant in many cases.

\section{Confrontation with unwanted information from social contacts}

Information management is an important component of coping with an illness. A big challenge for the informant is to recognise when information is desired or may be unhelpful or even harmful. ${ }^{26}$ That means that some patients and their social support collaborate in seeking or avoiding information, while others find their information management strategies working at cross purposes, even when the suggestions from others are well meant. Different perceptions about an individual's desire for information between the individual and potential information providers (eg, healthcare providers or supportive others) may result in behaviours that seem unresponsive or intrusive. ${ }^{26}$ Such experiences were common in our interviews. Some of our participants preferred to avoid thinking about their disease, at least from time to time, especially when they did not have any symptoms. During such times, they felt annoyed if family members, friends or other persons wanted to speak about their condition.

Another negative effect of talking about the disease is re-traumatisation as a result of participating in a support group. Members have to repeatedly listen to other group members' stories, which may reinforce negative feelings from the past or affect their current health status. ${ }^{27}$ Our participants reported similar experiences when listening to others in face-to-face encounters or reading about it in online support groups. Being exposed time and again to other people's problems with their health made them feel more anxious about their own well-being now and in the future.

\section{Confrontation with a possible negative future}

According to social comparison theory, originally authored by Festinger, ${ }^{28}$ social comparison occurs between people with similar problems, such as chronically ill people, helping them to evaluate their situation. ${ }^{29}$ In cases of 'downward comparison', ${ }^{30}$ people match themselves to persons who are doing worse than they are and thus increase self-esteem. This could result in feeling lucky that one is not in as bad a situation as the individual to whom the patient compares himself or herself $^{28}$ and further help them to gain information on how to avoid the same unfavourable situation. ${ }^{30}$ None of our interviewees told us about feeling better because of 
listening to peers who were feeling worse or described mainly negative experiences. However, they often spoke about feeling anxiety and uncertainty in general when listening to other people in support groups. Even if this exchange was seen as helpful, they still started worrying about their own course of illness and a possible worsening in the future. Online, there are many unpleasant reports about experiences with IBD. Some of our participants became very anxious about their own health and the possibilities of having the same problems in the near future after reading various 'horror stories' on the internet, especially when they read about symptoms that were familiar to them.

\section{Confrontation with people who are feeling much better than oneself}

Another form of social comparison is "upward comparison', that is, comparing oneself with a person who is better off. ${ }^{30}$ It may be particularly helpful in (online) support groups if the participants directly ask for information about how to improve their own situation. However, seeing others who are better off than oneself could also generate feelings of pessimism and frustration because patients might feel that they could never be as well off as some of their peers. ${ }^{30}$ Some of our participants told us about similar experiences. When they met other patients who were feeling better compared with them, they experienced more anxiety and uncertainty about why they were not getting better.

\section{Undesirable reactions}

The category of undesirable reactions contains reports from our participants about negative experiences with their close social network. The interviewees especially complained about not being treated 'normally', such as being pitied or stigmatised. Furthermore, they sometimes felt that their friends and families were either overreacting or indifferent to their illness.

\section{Pity}

Pity is a frequent negative experience reported by patients with chronic conditions. ${ }^{31}$ Pity, similar to distrust, avoidance or gossip, may also be a subtle form of stigmatisation by family members and friends. ${ }^{32}$ Patients and other sufferers fear pity because they do not want their partners to view them as 'sickly' and consequently leave the relationship. ${ }^{33}$ The experience of pity may lead to social isolation, alienation, lack of self-confidence, sadness or withdrawal, as well as the feeling of loneliness and restraints in conversations with other people on subjects related to their condition. ${ }^{31}$ Enacted stigma in the form of pity was also observed in a study with young patients with IBD. ${ }^{33}$ Several participants in this study gave examples of their friends, family or colleagues expressing sympathy towards them in a kindly manner, but this notion was articulated in a way that 'othered' the persons with IBD and, by doing so, emphasised their differentness. One woman in this study talked about her explicit rejection of others' pitying attitude towards her, simultaneously presenting herself as somebody who is strong-willed. ${ }^{34}$

The striking dismissal of pity in close relationships or in work places was probably the most noticeable negative effect of social support in our interviews, including somewhat hostile reactions towards sympathy. Pity was seen as a sign of weakness and being 'different', which for example led some participants to engage in somewhat reckless activities, just to prove that they did not change at all.

\section{Overreacting}

Family members and friends often have concerns and questions related to chronic illnesses of their loved ones. ${ }^{17}$ Some of them may even try to help by offering unsolicited and sometimes incorrect advice, for example, related to diet or medication changes. ${ }^{17}$ Similar interactions were seen as negative by some of our interview partners. They told us about various encounters where people in their social network did not seem to understand all the specifics about IBD and sometimes appraised the situation as very dramatic and therefore, in the opinion of the patients, as incorrect. Perceiving that others misunderstood IBD is a source of low mood which often led to social withdrawal, as participants in a British interview study reported. ${ }^{11}$ Several interview partners told us about conflicts with friends or family members where they tried to look after them or impose help, especially if it was not desired. Receiving unwanted social support was often experienced as an attack on independence and self-determination. Therefore, several participants felt that they were not in control, weak, needed help and thus were being dominated by the illness.

\section{'Positive' stigma}

Young patients with cancer in a qualitative study by Iannarino et $a l^{35}$ were frustrated when distant friends offered support after hearing about their diagnosis. They believed that people did it not out of genuine care but to relieve a sense of guilt or to satisfy their curiosity about the patients' experiences with a serious illness. A similar experience of a positive stigma was reported by one of our interview partners, a young woman. After the diagnosis, some people in her social network suddenly became interested in her. Similar to being pitied, this occurrence made her feel different than her peers-a negative experience. Other participants also reported being singled out as a result of their illness and that these newly emerging helpers had not sincerely supported them in the past.

\section{Online communication}

Online support groups are becoming a popular resource for a wide variety of medical and psychosocial issues. Receiving mutual social support can significantly improve health and well-being. ${ }^{36}$ Online support groups received similarly positive ratings than face-to-face support groups and are more often used by younger, better educated and wealthier people. ${ }^{37}$ It is possible to receive valuable support and advice at times when traditional sources of 
help are likely to be unavailable. ${ }^{38}$ Online communication is of particular benefit to patients suffering from chronic health conditions with functional limitations that may prevent them from attending regular meetings. ${ }^{39}$ Online support groups also offer an opportunity to remain entirely anonymous, which may be helpful for promoting self-disclosure and reducing feelings of stigma. ${ }^{38} 40$

Even if most studies focus on the benefits of online support groups, there is growing evidence to the contrary. ${ }^{16}$ Despite extensive searches in health, social sciences, communication and informatics literature, Eysenbach and colleagues, ${ }^{40}$ for example, failed to find robust indications of the health benefits of virtual communities and online support groups. Other studies go further and discuss negative aspects, even suggesting that internet communities can be harmful because they lead to attitude polarisation and increased prejudices among their members. ${ }^{37} 38$ Some authors have argued that the anonymity of online environments may lead to increased instances of disinhibited communication involving aggressive and hostile exchanges. ${ }^{38}$ Furthermore, concerns have also been raised over quality, hoaxes and spam, encouragement of suicide and privacy issues in internet groups. ${ }^{40}$ Similar experiences were very common among our participants, who used the internet to communicate with others or look for helpful suggestions. The interview partners told us about uncertainty with regard to trustworthiness of the information found online and about reservations and anxiety about their exchanges with other people with IBD in support groups on the internet.

\section{Working conditions}

Surprisingly, high levels of social support at work are correlated with high levels of emotional exhaustion, depersonalisation, long spells of absenteeism and high levels of physical symptoms. ${ }^{41}$ The mechanisms behind these correlations remain unclear. Working with IBD was generally a challenge for most of our participants because of symptoms like diarrhoea and fatigue. In addition, not everybody felt comfortable telling his or her coworkers about the disease. People with IBD tend to be afraid of losing their job or being made fun of at work, even more than in social contexts. ${ }^{42}$ Our data indicate that-in some cases-social support was the reason for these fears and experiences. For example, some of our participants complained about coworkers being too compassionate and forthcoming. Similar to some experiences with social support from friends and family, social support at work was associated with feelings of loss of control or not being able to handle the situation, not being the same person as before, or even not being 'normal' anymore.

\section{Dark side of social support}

A usual line of argument in the case of IBD is that avoidance behaviour, due to incontinence, stress, fatigue and other problems, leads to social isolation and-as a consequence-to feelings of social inadequacy and a lack of necessary societal skills. ${ }^{4}$ An alternative or complimentary line of argument could be that negatively perceived social support may be the reason for social withdrawal.

It seems paradoxical to think of social support in negative terms. Even if our participants discussed some negative effects, the question arises whether social support can really be negative-and, if so, why. For a possible explanation, we may apply Breithaupt's thesis of the dark side of empathy ${ }^{4344}$ to the social support paradox. In his eyes, empathy, as one of the chief motors of humanitarian aid, is based on two factors: temporal change and the scene of engagement. With the first factor, the empathiser expects that the situation of the victim will change over time so that the empathiser can withdraw, either physically or mentally. 'Scene of engagement' means that empathy is directed towards the victim and also, and perhaps even more, to the helper. Applying the first factor to social support, we could say that those who give social support expect temporal change and may urge the sufferer to channel efforts in a direction they consider favourable. With the second factor, we could say that supporters are interested in putting themselves in the limelight as helpers who are appreciated by others due to their good deeds.

Breithaupt goes a step further in illuminating the dark sides of empathy, namely, a tendency to radicalise conflict and a pleasure that the empathiser may derive from the pain or misfortune of others, a sort of 'sadistic empathy'. ${ }^{434}$ Applied to social support, we could say that supporters tend to reinforce and radicalise the troubles and needs of the sufferers and do not realise if sufferers do not like talking about their troubles. Moreover, social support can give birth to a sort of pleasure if the supporter tries to imagine the happiness of the one he or she helps, so that support is turned into a self-focused affair for the supporter. Even worse, as long as there is pain, suffering and need, the supporter derives a sense of self-importance and a degree of pleasure from the suffering that he or she may be inclined to reinforce. Of course, we did not study the motives and actions of those who offer social support, but if Breithaupt's empathy thesis is also true for social support, the participants in our study may have experienced, at least from time to time, the dark sides of social support as a negative dynamic that puts them under pressure.

\section{Practical implications}

Our findings could help medical professionals as well as friends, family members, partners and peers of persons with IBD to become more sensitive to the dark sides of social support. While many of our participants found social support to be a positive factor, others told us about the negative effects as well. The accounts of our participants can help people in their social environment to better recognise and avoid offering unwanted information or other undesirable forms of support that could complicate the attempts of patients with IBD to adjust to their illness. For example, possible supporters should 
ask themselves some questions before offering support (eg, will my support increase the feeling of being ill; will my support enhance the feeling to be different; is my support 'egoistic'?). Vice versa, people with IBD should not feel pressurised to look for social support as the only and single way to successful coping and they should not be blamed if they keep some distance to others, at least from time to time. However, patients may have problems to follow these recommendations since it is known that they usually show extreme social agreement and low level of assertiveness in interpersonal contacts. ${ }^{45}$ This may even be a further reason why they perceive social support often as negative. So, health providers and others should help people with IBD to become more assertive, that is, to be able to stand up for own wishes in a calm and positive way and thus to protect themselves against negative forms of social support.

\section{Strengths and limitations of the study}

The most common critique points of qualitative research are the possible influence of the personality and the training of the researcher on the data collection and analysis as well as the small number of participants. Both arguments do apply to our study. We tried to exclude personal biases and idiosyncrasies when selecting the quotes or interpreting the data by working in an interdisciplinary team consisting of medical doctors, a psychologist and sociologists.

A selection bias has to be discussed. Since one aim of our website project was to publish the interviews or parts of them on www.krankheitserfahrungen.de, some people addressed via advertisements in newspapers, online forums and so on might have considered this an argument to decline. It is possible that these decliners have certain characteristics and experiences, for example, very negative or positive experiences with social support that are under-represented in our interviews.

As for the possible strengths of this study, we believe that the recruitment, using a maximum variation method, allowed us to collect and to show a broad range of experiences of different people with IBD. Additionally, the open-ended narrative approach in conducting the interviews allowed the participants to talk about and emphasise the issues that are important to them, which would not have been addressed in a quantitative study. Therefore, we were able to see the importance of the negative effects of social support-a topic that has not received much attention in research.

\section{CONCLUSION}

To the best of our knowledge, this was the first qualitative study to specifically examine the negative effects of social support in patients with IBD in detail. Judging from the experiences of our participants, social support sometimes has a negative impact on people with IBD. Furthermore, our participants complained about not getting the reactions and support from their social network that they desired. Therefore, some of them developed strategies to prevent coming into social contact with others or stopped talking about their disease entirely. This may lead to fewer social contacts and even deteriorating health. The results of this study could be used to encourage persons with IBD to voice their support preferences to their friends, family, coworkers or even peers in face-to-face and online support groups. Helping individuals participate more effectively in difficult conversations could empower them to better take advantage of the assistance available to them through close relationships. Furthermore, doctors and allied health personnel should inform family members of possible unwanted effects from social support.

Contributors AP and WH conceived and designed the study. AP and WH participated in the acquisition, analysis and interpretation of data. AP drafted a first version of the manuscript. AP and WH critically reviewed the manuscript and approved this version to be published.

Funding This work was supported by a research grant from the German statutory pension insurance scheme (Deutsche Rentenversicherung Bund); research grant no. 0421-FSCP-Z139.

Disclaimer Deutsche Rentenversicherung Bund had no further involvement in the study.

Competing interests None declared.

Patient consent Obtained.

Ethics approval Ethical approval received from the local ethics committee of the University Medical Center Göttingen (no. 17/1/07).

Provenance and peer review Not commissioned; externally peer reviewed.

Data sharing statement No additional data are available.

Open access This is an open access article distributed in accordance with the Creative Commons Attribution Non Commercial (CC BY-NC 4.0) license, which permits others to distribute, remix, adapt, build upon this work non-commercially, and license their derivative works on different terms, provided the original work is properly cited, appropriate credit is given, any changes made indicated, and the use is non-commercial. See: http://creativecommons.org/licenses/by-nc/4.0/.

\section{REFERENCES}

1. Santos RMD, Carvalho ATP, Silva KDS, et al. Inflammatory bowel disease: outpatient treatment profile. Arq Gastroenterol 2017;54:96-100.

2. Cosnes J, Gower-Rousseau C, Seksik P, et al. Epidemiology and natural history of inflammatory bowel diseases. Gastroenterology 2011;140:1785-94.

3. Sewitch MJ, Abrahamowicz M, Bitton A, et al. Psychological distress, social support, and disease activity in patients with inflammatory bowel disease. Am J Gastroenterol 2001;96:1470-9.

4. Kemp K, Griffiths J, Lovell K. Understanding the health and social care needs of people living with IBD: a meta-synthesis of the evidence. World J Gastroenterol 2012;18:6240-9.

5. Mao P, Luo A, Yang J, et al. Effect of social support and coping styles on the stress and mental health in relatives of patients with traumatic brain injury. Zhong Nan Da Xue Xue Bao Yi Xue Ban 2015;40:303-10.

6. Prang KH, Berecki-Gisolf J, Newnam S. Recovery from musculoskeletal injury: the role of social support following a transport accident. Health Qual Life Outcomes 2015;13:97.

7. Oliveira S, Zaltman C, Elia C, et al. Quality-of-life measurement in patients with inflammatory bowel disease receiving social support. Inflamm Bowel Dis 2007;13:470-4.

8. Wang J, Chen Y, Tan C, et al. Family functioning, social support, and quality of life for patients with anxiety disorder. Int J Soc Psychiatry 2016;62:5-11.

9. Croezen S, Picavet HS, Haveman-Nies A, et al. Do positive or negative experiences of social support relate to current and future health? Results from the Doetinchem Cohort Study. BMC Public Health 2012;12:65.

10. Guruge S, Thomson MS, George U, et al. Social support, social conflict, and immigrant women's mental health in a Canadian 
context: a scoping review. J Psychiatr Ment Health Nurs 2015;22:655-67.

11. Jordan $C$, Ohlsen R, Hayee B, et al. A qualitative study exploring the experience of people with IBD and elevated symptoms of anxiety and low mood and the type of psychological help they would like. Psychol Health 2018;33:634-51.

12. Devylder JE, Gearing RE. Declining social support in adolescents prior to first episode psychosis: associations with negative and affective symptoms. Psychiatry Res 2013;210:50-4.

13. Nilsson MI, Petersson LM, Wennman-Larsen A, et al. Adjustment and social support at work early after breast cancer surgery and its associations with sickness absence. Psychooncology 2013;22:2755-62.

14. McTernan WP, Dollard MF, Tuckey MR, et al. Enhanced co-worker social support in isolated work groups and its mitigating role on the work-family conflict-depression loss spiral. Int J Environ Res Public Health 2016;13:382.

15. Aglen B, Hedlund M, Landstad BJ. Self-help and self-help groups for people with long-lasting health problems or mental health difficulties in a Nordic context: a review. Scand J Public Health 2011;39:813-22.

16. Jackson AM, Gregory S, McKinstry B. Self-help groups for patients with coronary heart disease as a resource for rehabilitation and secondary prevention - what is the evidence? Heart Lung 2009;38:192-200.

17. Leshem RN. Inflammatory bowel disease support groups: a primer for gastroenterology nurses. Gastroenterol Nurs 2003;26:246-50.

18. Frohlich DO, Zmyslinski-Seelig A. The presence of social support messages on YouTube videos about inflammatory bowel disease and ostomies. Health Commun 2012;27:421-8.

19. Brashers DE, Hsieh E, Neidig JL, et al. Managing uncertainty about illness: health care providers as credible authorities. In: Le Poire BA, Dailey RM, eds. Applied interpersonal communication matters. family, health and community relations. New York: Peter Lang, 2006:219-40

20. Rogala L, Miller N, Graff LA, et al. Population-based controlled study of social support, self-perceived stress, activity and work issues, and access to health care in inflammatory bowel disease. Inflamm Bowel Dis 2008;14:526-35.

21. Katz L, Tripp DA, Ropeleski M, et al. Mechanisms of quality of life and social support in inflammatory bowel disease. J Clin Psychol Med Settings 2016;23:88-98.

22. Ziebland S, Herxheimer A. How patients' experiences contribute to decision making: illustrations from DIPEx (personal experiences of health and illness). J Nurs Manag 2008;16:433-9.

23. Palant A, Koschack J, Rassmann S, et al. "And then you start to loose it because you think about Nutella": the significance of food for people with inflammatory bowel disease-a qualitative study. BMC Gastroenterol 2015;15:93.

24. Charmaz K. Constructing Grounded Theory: a practical guide through qualitative analysis. Thousand Oaks, CA: Sage 2006.

25. Creswell JW, Miller DL. Determining validity in qualitative inquiry. Theory Pract 2000;39:124-30.

26. Brashers DE, Goldsmith DJ, Hsieh E. Information seeking and avoiding in health contexts. Hum Commun Res 2002;28:258-71.
27. Dyregrov K, Dyregrov A, Johnsen I. Positive and negative experiences from grief group participation: a qualitative study. Omega 2013;68:45-62.

28. Festinger L. A theory of social comparison processes. Human Relations 1954;7:117-40.

29. Dibb B, Yardley L. How does social comparison within a self-help group influence adjustment to chronic illness? A longitudinal study. Soc Sci Med 2006;63:1602-13.

30. Hodges L, Dibb B. Social comparison within self-help groups: views of parents of children with Duchenne muscular dystrophy. $J$ Health Psychol 2010;15:483-92.

31. Bulinski L. Social reintegration of TBI patients: a solution to provide long-term support. Med Sci Monit 2010;16:14-23.

32. Moses T. Being treated differently: stigma experiences with family, peers, and school staff among adolescents with mental health disorders. Soc Sci Med 2010;70:985-93.

33. Kaushansky D, Cox J, Dodson C, et al. Living a secret: disclosure among adolescents and young adults with chronic illnesses. Chronic IIIn 2017;13:49-61.

34. Saunders B. Stigma, deviance and morality in young adults accounts of inflammatory bowel disease. Sociol Health IIIn 2014;36:1020-36.

35. lannarino NT, Scott AM, Shaunfield SL. Normative social support in young adult cancer survivors. Qual Health Res 2017;27:271-84.

36. Isupova OG. Support through patient internet-communities: lived experience of Russian in vitro fertilization patients. Int J Qual Stud Health Well-being 2011;6:5907.

37. Huber J, Muck T, Maatz P, et al. Face-to-face vs. online peer support groups for prostate cancer: a cross-sectional comparison study. $J$ Cancer Surviv 2018;12:1-9.

38. Malik S, Coulson NS. The therapeutic potential of the internet: exploring self-help processes in an internet forum for young people with inflammatory bowel disease. Gastroenterol Nurs 2011;34:439-48.

39. Blackstock OJ, Shah PA, Haughton LJ, et al. HIV-infected women's perspectives on the use of the internet for social support: a potential role for online group-based interventions. J Assoc Nurses AIDS Care 2015;26:411-9.

40. Eysenbach G, Powell J, Englesakis M, et al. Health related virtual communities and electronic support groups: systematic review of the effects of online peer to peer interactions. BMJ 2004;328:1166.

41. Deelstra JT, Peeters MC, Schaufeli WB, et al. Receiving instrumental support at work: when help is not welcome. J Appl Psychol 2003;88:324-31.

42. Kim YS, Jung SA, Lee KM, et al. Impact of inflammatory bowel disease on daily life: an online survey by the Korean Association for the Study of Intestinal Diseases. Intest Res 2017;15:338-44.

43. Breithaupt F. Why empathy is not the best basis for humanitarianism (Global Cooperation research Papers; 9). Duisburg: Centre for Global Cooperation Research, 2015.

44. Breithaupt F. The dark sides of empathy. Ithaca, NY: Cornell Univ. Press. In Press.

45. Rakovec-Felser Z. The biopsychosocial model of treatment the patients with inflammatory chronic bowel disease. Coll Antropol 2011;35:453-61. 